\title{
Avaliação $360^{\circ}$ : das empresas direto às escolas de tempo integral no estado de São Paulo
}

\author{
$360^{\circ}$ evaluation: from business straight to full-time schools \\ in the state of São Paulo \\ Evaluación $360^{\circ}$ : de las empresas directamente a las escuelas de tiempo \\ completo en el estado de São Paulo \\ SELMA BORGHI VENCO \\ ROSEMARY MATTOS
}

\begin{abstract}
Resumo: O presente artigo objetiva debater um dos aspectos da gestão do trabalho implementado pela Secretaria Estadual de Educação, no âmbito do Programa de Ensino Integral (PEI): a avaliação 360 graus, a qual integra um conjunto de procedimentos da avaliação de desempenho dos profissionais do magistério. As reflexões aqui construídas associam duas pesquisas, uma de caráter documental; e outra qualitativa, por meio de entrevistas semi-estruturadas realizadas junto a diretores.as das escolas estaduais. Constata-se que a política educacional paulista permanece coerente aos princípios gerencialistas e adota mensurações comportamentais, com vistas a enquadrar os profissionais vinculados ao Programa e adota como medida punitiva o desligamento do PEI, que bonifica em $75 \%$ os aderentes. Mesmo frente a um aumento salarial significativo, há evidências de abandono do Programa, tendo em vista as pressões vivenciadas e a desconfiguração do trabalho intelectual.
\end{abstract}

Palavras-chave: avaliação 360o; escola de tempo integral; política educacional

Abstract: This article aims to discuss one of the aspects of work management implemented by the State Department of Education within the framework of the Integral Education Program (PEI): the 360 degree evaluation, which integrates a set of performance assessment procedures for teachers'. The reflections built here associate two pieces of research, one of documentary character; and a qualitative one, through semi-structured interviews carried out with the directors of state schools. It can be seen that the educational policy of São Paulo remains consistent with the managerial principles and adopts behavioral measures, aiming at framing the professionals linked to the Program and adopts as a punitive measure the dismissal of the PEI, which $75 \%$ of the adherents. Even in the face of a significant salary increase, there is evidence of abandonment of the Program, given the pressures experienced and the misconfiguration of intellectual work.

Keywords: $360^{\circ}$ evaluation; full-time school; educational politics 
Resumen: El presente artículo objetiva debatir uno de los aspectos de la gestión del trabajo implementado por la Secretaría Estatal de Educación, en el marco del Programa de Enseñanza Integral (PEI): la evaluación 360 grados, la cual integra un conjunto de procedimientos de la evaluación de desempeño de los profesionales del magisterio. Las reflexiones aquí construidas asocian dos investigaciones, una de carácter documental; y otra cualitativa, por medio de entrevistas semiestructuradas realizadas junto a directores de las escuelas estatales. Se constata que la política educativa paulista sigue siendo coherente a los principios gerencialistas y adopta mediciones comportamentales, con el reto de encuadrar a los profesionales vinculados al Programa y adopta como medida punitiva la desvinculación del PEI, que bonifica en el 75\% a los adherentes. Incluso frente a un aumento salarial significativo, hay evidencias de abandono del Programa, teniendo en vista las presiones vivenciadas y la desconfiguración del trabajo intelectual.

Palabras clave: evaluación 360 o; escuela de tiempo completo; política educativa.

\section{INTRODUÇÃO}

O presente artigo objetiva debater um dos aspectos da gestão do trabalho implementado no governo paulista, mais especificamente na Secretaria Estadual de Educação, que ocorre no âmbito do Programa de Ensino Integral (PEI): a avaliação 360 graus. Essa ${ }^{1}$, integra um conjunto de procedimentos da avaliação de desempenho dos profissionais do magistério.

A hipótese que sustenta a análise reside no pressuposto de que a Secretaria de Estado da Educação de São Paulo (SEESP)², adota novas estratégias voltadas ao controle do trabalho dos profissionais que atuam no PEI, oriundas do modelo empresarial.

As reflexões aqui construídas associam duas pesquisas em andamento, quais sejam: uma, 'A política educacional no Brasil e na França: um estudo sobre as relações de trabalho no território)'3; e, outra, 'O Gestor Escolar no Programa de Ensino Integral do Estado de São Paulo (2012-2017): exigências análogas às do gerente do setor privado'. A primeira, ainda em sua primeira fase de sistematização

Cf Resolução SE-68, de 17-12-2014, que dispõe sobre o processo de avaliação dos profissionais que integram as equipes escolares das escolas estaduais do Programa Ensino Integral, a avaliação de desempenho é constituída pelas seguintes etapas: 1) Avaliação $360^{\circ}$; 2) Avaliação de Resultado; 3) Consolidação ;4) Calibragem e 5) Devolutiva.

2 A despeito da alteração da sigla da Secretaria da Educação do Estado de São Paulo ter sido alterada pela Resolução 18 de 02/05/210, optou-se por conserver a anterior, uma vez que a pesquisa documental realizada refere-se ao período concernente à denominação SEESP e não SEDUC, como desde maio de 2019. 
da documentação da política, é de cunho documental e a segunda se trata de uma pesquisa qualitativa, na qual foram entrevistados doze diretores e diretoras da rede de ensino estadual paulista.

O tema do artigo inscreve-se no cenário da valorização da extensão do tempo de permanência nas escolas, por parte da SEESP, que, por influência dos organismos internacionais, a exemplo da OCDE, é tida como condição sine qua non para garantia de melhoria da qualidade da educação. A mesma medida, no entanto, é compreendida como uma forma de contenção da marginalidade (PARO, 1988) e solução para as famílias trabalhadoras, que não contam com equipamentos sociais e ou apoios públicos de outras naturezas para permanecerem com filhos e filhas nos horários de trabalho, especialmente das mães (VENCO, 2017).

A noção de qualidade da educação, segundo Fonseca (2009) perseguiu, historicamente, o atendimento das demandas provenientes do setor empresarial, apoiado no discurso da altivez, presente no papel ativo do cidadão na construção da riqueza do país, conforme propalado pelo Ministério da Educação em 1971 (apud FONSECA, 2009). Tal perspectiva permanece inabalada e a ela somamse, especialmente a partir dos anos 1990, estratégias de mensuração baseadas em provas homogêneas aplicadas em contextos altamente heterogêneos, dados, sobretudo à profunda desigualdade social brasileira, sendo o estado de São Paulo um dos pioneiros na implementação de tais medidas.

No contexto da Reforma Educacional ocorrida em 1995, a Lei de Diretrizes e Bases da Educação Nacional (LDB, 1996) já indicava a premência de se oferecer progressivamente o ensino em tempo integral, corroborada pelo Plano Nacional de Educação 2014-20244, cuja meta para o período será alcançar metade das escolas do país nesse regime, contando com sete horas diárias de aprendizagem.

A Secretaria Estadual de Educação de São Paulo, por sua vez, no uso da autonomia que lhe é conferida por lei, criou em 2012 seu próprio Programa de expansão da jornada diária nas escolas, que passamos a analisar.

\section{O PROGRAMA DE ENSINO INTEGRAL (PEI) NO ESTADO DE SÃO PAULO}

A educação integral assume diversas compreensões ao longo da história, abrangendo um leque que perpassa a Paideia (JAEGER, 1995), no sentido da articulação dos diversos campos do conhecimento, a tecida por Bakunin (1979) cuja formação desierarquizada permita construir um pensamento reflexivo 
capaz de levar à emancipação pessoal e coletiva. Com fundamentação em tais perspectivas, visa-se a problematizar em que medida o conceito de educação integral é metamorfoseado para uma ideia, que pretende ser sinônima, de maior tempo de permanência nas escolas.

Para a Secretaria paulista, o prolongamento da jornada diária se constitui em: "uma estratégia fundamental para viabilizar metodologias que deverão elevar os indicadores de aprendizagem dos estudantes em todas as suas dimensões."(SEESP,s/d, p. 115)

Tomando como base as ações desenvolvidas pelo governo paulista para a educação, observa-se que, em 2011, foi criado o Programa 'Compromisso de São Paulo', sustentado por cinco pilares, apresentados pela SEESP, com o objetivo de: 1. Valorizar o capital humano, por meio da contratação de novos professores e de nova política salarial; 2. Criar a Escola Virtual do Estado de São Paulo, dedicada a promover cursos para crianças do $4^{\circ}$ ao $6^{\circ}$ anos sobre como se planejar financeiramente. Nas palavras da Secretaria: "Mas, com tão pouca idade, isso é necessário? A resposta é sim. Quanto mais cedo os pequenos souberem lidar com finanças, menos problemas com dinheiro terão na fase adulta. (...)"*6. O jogo já está sendo utilizado em algumas escolas (...) e é a base da disciplina eletiva 'Dinheirama'. Nessa matéria, estudantes de 11 e 12 anos aprendem noções do mundo das finanças, demonstrando, assim, atrelamento ao Programa Internacional de Avaliação dos Estudantes (PISA), que incluiu, desde 2015, a 'competência financeira' como área de exame ; 3. Implementar o 'Programa de Educação Integral', com dedicação exclusiva dos docentes. A despeito de conceder uma gratificação a eles, ressalte-se que essa não é incorporada ao salário podendo ser cancelada a qualquer momento; 4. Fomentar a 'Gestão organizacional e financeira', voltada ao aprimoramento da infra-estrutura, transporte e merenda escolar; 5. Recuperar o Programa Escola da Família, como forma de 'mobilização da sociedade', com vistas a engajar a sociedade no debate sobre a qualidade da educação.

A despeito do conjunto de pilares ser de grande interesse para compreender e problematizar a política educacional paulista, privilegia-se a análise do terceiro deles, o PEI, posto ser nele a incidência da ferramenta de avaliação.

\footnotetext{
5 Disponível em <https://www.educacao.sp.gov.br/a2sitebox/arquivos/documentos/342.pdf> Acesso em 18.set.2018

6 Cf. Disponível em <http://www.educacao.sp.gov.br/noticia/ensino-fundamental/educacao-eevesp-oferecem-jogo-online-sobre-educacao-financeira $>$ Acesso em 18.set.2018

7 Disponível em http://www.educacao.sp.gov.br/noticia/ensino-fundamental/educacao-e-evespoferecem-jogo-online-sobre-educacao-financeira/ Acesso em 18.set.2018
} 
De acordo com a SEESP, o principal objetivo do PEI é "formar jovens autônomos, solidários e competentes"(SEESP, 2014, p. 13), por meio da excelência acadêmica, articulada à edificação do projeto de vida dos estudantes, de um currículo composto pela Base Nacional Comum Curricular (BNCC) e pela parte diversificada, focalizado nos quatro pilares da educação adotados pela UNESCO: o aprender a conhecer, aprender a fazer, aprender a viver juntos e aprender a ser.

Observa-se, pela análise documental, a presença de um modelo pedagógico sustentado por um tripé que elege o projeto de vida, uma disciplina constante da grade curricular, como leitmotiv para planejar o futuro, de maneira, segundo o documento, a, de um lado, para os anos finais do Ensino Fundamental, dar continuidade aos estudos, e de outro, destinado aos do Ensino Médio, abarcar anseios pessoais e profissionais, configurando, assim, um diálogo direto e exclusivo com o mercado de trabalho e adotando valores caros à lógica do empreendedorismo:

Os educadores que atuam nas Escolas de Ensino Integral incentivam cada aluno a sonhar e a fazer o esforço necessário para realizar seus sonhos. Há uma plena ciência de que ao lado desse incentivo a escola deve oferecer apoio para que seus alunos tenham possibilidades reais de atingir seus anseios. (SEESP, s/d, p.20, grifo nosso)

Ressalte-se que, para elaboração da política do PEI, a SEESP teve como referência o Programa de Ensino Integral de Pernambuco, implantado em $2008^{8}$, e do Rio de Janeiro com o Ginásio Carioca em 2011, sob a direção do Instituto de Corresponsabilidade pela Educação (ICE), o qual teve importante atuação nesse processo, por meio da venda de consultoria junto ao órgão do estado.

Em São Paulo, o PEI é iniciado timidamente em 2012, uma vez que apenas dezesseis das mais de cinco mil escolas foram selecionadas para integrá-lo. Observa-se, com base no Gráfico 1, que, em seis anos, o Programa apresentou expressivo aumento, totalizando trezentas e sessenta e quatro escolas, ainda assim elevação, passando das iniciais 16 para 364 escolas, mas atingindo apenas 7\% do conjunto e estabelecimentos em 2018.

8 Sobre o Programa de Ensino Integral em Pernambuco ver http://www.educacao.pe.gov.br/ portal/?pag=1\&men=70 acesso em 21/02/2018, instituído pela Lei Complementar n ${ }^{\circ} 125$ de 10/07/2008

9 Sobre a implantação do PEI no município do Rio de Janeiro ver http://www.rio.rj.gov.br/web/ sme/exibeconteudo?id=2285016 acesso em 21/02/2018 e Decreto no 32.672 de 18/08/ 2010. Disponível em https://leismunicipais.com.br/a/rj/r/rio-dejaneiro/decreto/2010/3267/32672/decreto-n-32672-2010-cria-oprograma-ginasio-carioca-no-ambito-dasecretaria-municipal-de-educacao-e-da-outras-providencias acesso em $21 / 02 / 201$ 


\section{Gráfico 1 - Escolas estaduais paulistas, sob regime PEI - 2012-2018 ( $\mathrm{n}^{\mathrm{o}}$ abs)}

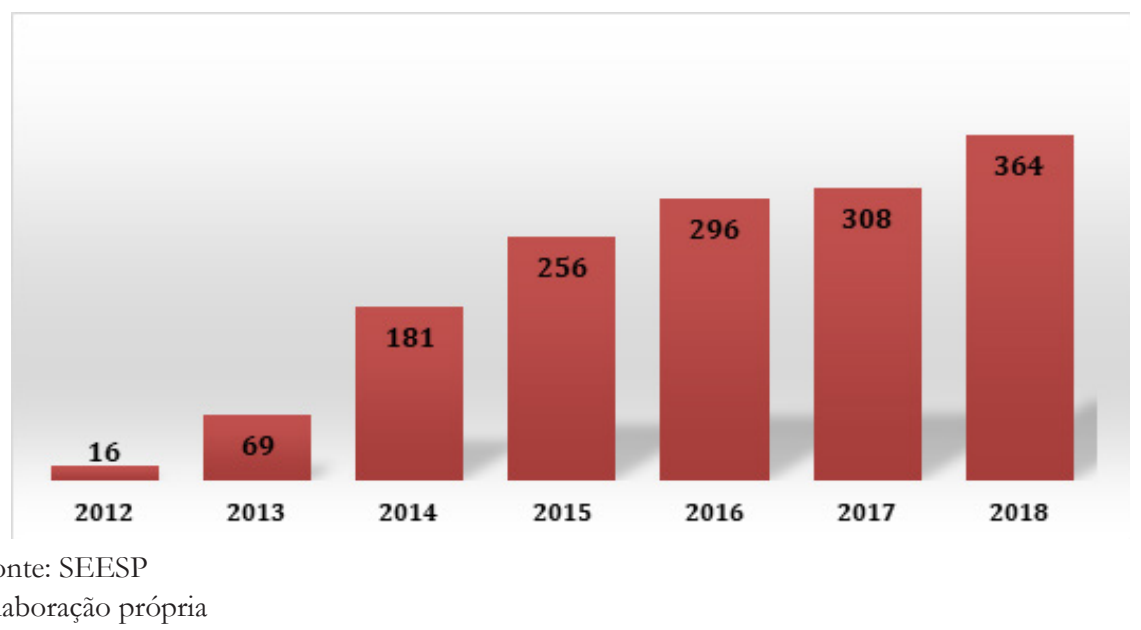

Para fazer frente ao novo modelo pedagógico, a Secretaria adotou novas formas de avaliação de desempenho dos que atuam em regime de dedicação exclusiva nas escolas do PEI. E, por meio da Resolução SE-68, de 17-12-2014, define, em seu art. $1^{\circ}, \S 2^{\circ}$, que os profissionais que continuarão a compor o quadro das escolas PEI após o processo avaliativo, bem como os macroindicadores que o nortearão a partir da avaliação: das competências, da atuação profissional, da calibragem para ajustes e avaliação final acompanhado da devolutiva.

\section{AVALIAÇÃO DE DESEMPENHO E A FERRAMENTA 360}

Pondera-se, primeiramente, que a avaliação da força de trabalho é tema recorrente na teoria das organizações. Desde Friedrich Taylor (1990), no início do século XX, a partir da proposição dos princípios de administração - por ele concebida como científica -, a seleção e permanente avaliação dos trabalhadores são aspectos centrais para lograr ganhos de produtividade. Mesmo o autor não tendo explicitado literalmente a dimensão avaliativa, essa se expressa ao longo de toda sua obra, a partir dos destaques para bonificações e aceite da rígida organização do trabalho acompanhadas de idênticas formas de controle.

Da teoria clássica à das relações humanas as concepções sofrem modificações significativas concernentes ao ambiente organizacional, com reflexos diretos no comportamento e no aumento da produtividade. A organização passa a ser concebida como um sistema social, conferindo-se ênfase à melhoria das 
condições ambientais e aos comportamentos dos trabalhadores, tentando forjar um clima ilusório de ruptura com a alienação no trabalho, com consequente ganhos de produtividade.

Brandão e Guimarães (2001) ressaltam que as corporações modernas requerem processos avaliativos, uma vez que o resultado do trabalho deriva da articulação entre as competências individuais e o clima organizacional. Os mesmos autores ressaltam as transformações sofridas pela avaliação no século $\mathrm{XX}$, a qual passa de um modelo 'de mão única', no qual apenas o empregador avalia o conjunto de trabalhadores, passando para a 'bilateral', onde chefias e chefiados debatem aspectos relacionados ao processo de trabalho e alcance de resultados, e, por fim, a "avaliação $360^{\circ}$ ”, por eles definida como "a avaliação do empregado por clientes, pares, chefe e subordinados". (idem, p.12)

Nesse contexto, cabe apontar as múltiplas conotações assumidas pelo termo competências e sua transposição à educação. Ropé e Tanguy (1997) recuperam a definição dada elo dicionário Larousse Comercial, de 1930:

\footnotetext{
Nos assuntos comerciais e industriais, a competência é o conjunto de conhecimentos, qualidades, capacidades e aptidões que habilitam para a discussão, a consulta, a decisão de tudo o que concerne seu ofício...Ela supõe conhecimentos fundamentados...geralmente, considera-se que não há competência total se os conhecimentos teóricos não forem acompanhados das qualidades e da capacidade que permitem executar as decisões sugeridas (ROPÉ \& TANGUY, 1997, p.16)
}

Durand (2006) concebe "competências" como uma articulação sustentada por um tripé composto por: a) atitude (savoir-être) orientada pela cultura; b) conhecimento (savoir), pela informação e formação, além do grau de especialização; e, c) prática (savoir-faire), permeada por técnicas e tecnologias.

A Secretaria Estadual de Educação de São Paulo, por sua vez, partilha em seus documentos e condutas da perspectiva que considera tais proposições desprovidas de caráter instrumental, posto que o tripé acima exposto não avaliza, pela concepção adotada, inovações no ambiente organizacional. A interpretação do conceito adotado pelo órgão público se expressa na formulação do currículo paulista:

Competências, nesse sentido, caracterizam modos de ser, de raciocinar e de interagir, que podem ser depreendidos das ações e das tomadas de decisão em contextos de problemas, de tarefas ou de atividades.[...] Graças a elas, podemos inferir, hoje, se a escola como instituição está cumprindo devidamente o papel que se espera dela (SÃO PAULO, 2008, p. 12). 
Importante destacar que a noção de competência na educação não é nova, pois, desde meados dos anos 1990, é empregada na política educacional paulista. Tal adoção revela uma face sustentada pela racionalidade e respondendo à lógica pragmática da mensuração de resultados, aqui compreendida como fonte limitadora da construção do conhecimento, tornando-o crescentemente enquadrado e com margens restritas à reflexão (BERTAGNA et al. 2018)

Os documentos institucionais da SEESP sobre a gestão de desempenho recuperam as transformações histórica ocorrida no campo teórico da "gestão de pessoas" e explicitam:

Que essas transformações são motivadas pelo surgimento de um novo contrato psicológico entre as pessoas e as organizações, fruto de um ambiente mais competitivo, em que as organizações, para sobreviver, precisam se manter em contínuo processo de desenvolvimento, o qual depende diretamente da capacidade de contribuição das pessoas que as compõem (SEE-SP, 2010, p. 10)

Assim, apreende-se que a matriz teórica orientadora das ações em gestão direciona sua opção para a "gestão de pessoas por competência", a qual prevê uma sucessão de processos que abarcam desde o recrutamento e a seleção ao desligamento dos trabalhadores e trabalhadoras, passando, necessariamente, pela avaliação de desempenho e desenvolvimento.

Novas formas de avaliação ganham força no bojo da globalização, momento que as empresas perseguindo seu perpetuum mobile, a obtenção de lucros, são levadas a acirrar os níveis de competitividade e a maximização de resultados.

Um dos aspectos da avaliação nas empresas é a 'identificação de lideranças’. Bacon (1999) informa que nas grandes empresas são despendidos até $25 \%$ do tempo dos dirigentes na formação de líderes, aspecto não restrito a programas de capacitação e, sim, a um conjunto de ações extraordinárias, capazes de mobilizar e associar as faces do tripé que conforma as competências, conforme mencionado anteriormente.

Nesse contexto de extrema concorrência empresarial, as organizações alçam a avaliação 360 graus, como sinal de modernização na apreciação do quadro funcional, substituindo a visão unilateral da chefia imediata pelas opiniões dos pares.

Todavia, essa ferramenta não é recente. De acordo com Corbin (2012) ela foi concebida durante a $2^{\mathrm{a}}$ Guerra Mundial pelos alemães, posteriormente adotada pela Esso Research and Engineering Company nos anos 1950 e propagada aos 
países industrializados, especialmente embalada pela escola de relações humanas. No Brasil, as análises teóricas concentram publicações nos anos 2000 e ela chega ao setor público no estado de São Paulo, em especial, na área Educação Básica em 2012 com a implementação do PEI, inicialmente em 16 escolas estaduais.

Oinstrumento, portanto, tem como objetivo a avaliaçãodo comportamento dos profissionais por meio de competências definidas previamente, promovida por uma múltipla ação que envolve diversos níveis hierárquicos, superiores e inferiores ao posto que ocupam e, em algumas situações, inclusive os clientes externos. O feedback retorna ao trabalhador com indicativos de melhorias para diversos pontos. (BACON, 1999; WALDMAN et al. 1998; BRACKEN et al, 2001).

Os derivados da avaliação, contudo, são igualmente utilizados pelos altos executivos das empresas com vistas a: identificar conflitos e ou distanciamentos entre os objetivos da organização e dos funcionários, bem como tomar decisões acerca da mobilidade no plano de carreira.

Neeshu (2016) realiza um balanço entre as vantagens e desvantagens dessa avaliação e destaca a positividade na possibilidade de encorajar o autodesenvolvimento, no rompimento da unilateralidade nos julgamentos das equipes e o fortalecimento da cultura da empresa calcada no ponto de vista do conjunto de trabalhadores.

Entre as dimensões negativas do processo, o mesmo autor enfatiza a complexidade e demora na aplicação da ferramenta, o tensionamento no clima organizacional e as dificuldades de implementar ações resultantes da avaliação.

\section{AVALIAÇÃO $360^{\circ}$ : PADRONIZAÇÃO E PRESCRIÇÃO DE COMPORTAMENTOS?}

De acordo com a SEESP, a avaliação $360^{\circ}$ se constitui em uma das etapas do processo da avaliação de desempenho dos professores e gestores (diretor, vice diretor e coordenadores pedagógicos) - assim denominados pela política educacional do estado de São Paulo -, que trabalham nas escolas que participam do PEI. Tal avaliação é orientada por material instrucional específico "Modelo de Desempenho das Equipes Escolares", o qual define as etapas do processo de avaliação. Dessa forma, indicam que:

A Avaliação de Desempenho dos profissionais tem por objetivo identificar as competências e os resultados esperados não observados para que sejam planejadas e promovidas ações de desenvolvimento profissional, tendo como referência o Mapa de Competências e as Premissas do Programa Ensino Integral. ( SEESP, 2014, p.2) 
A avaliação $360^{\circ}$, aplicada no PEI, é, a exemplo das empresas privadas, focalizada em competências observadas, via comportamento dos profissionais no cotidiano do seu trabalho, por meio da construção de um mapa de competências. Ou seja, tal medida explicita haver uma permanente acompanhamento e análise de condutas que extrapolam o conhecimento acadêmico, conforme pode ser verificado no Quadro 2:

\section{Quadro 2 - Expectativas profissionais no PEI}

\begin{tabular}{|c|c|}
\hline COMPETÊNCIA & MACROINDICADOR \\
\hline Protagonismo & $\begin{array}{l}\text { • Respeito à individualidade } \\
\text { - Promoção do protagonismo juvenil } \\
\text { • Protagonismo sênior }\end{array}$ \\
\hline $\begin{array}{l}\text { Domínio do conhecimento e } \\
\text { contextualização }\end{array}$ & $\begin{array}{c}\text { - Domínio do conhecimento } \\
\text { • Didática } \\
\text { • Contextualização }\end{array}$ \\
\hline $\begin{array}{c}\text { Disposição ao } \\
\text { autodesenvolvimento } \\
\text { contínuo }\end{array}$ & $\begin{array}{c}\text { • Formação contínua } \\
\text { •Devolutivas } \\
\text { • Disposição para mudança }\end{array}$ \\
\hline $\begin{array}{l}\text { Comprometimento com o } \\
\text { processo e resultado }\end{array}$ & $\begin{array}{l}\text { - Planejamento } \\
\text { - Execução } \\
\text { - Reavaliação }\end{array}$ \\
\hline $\begin{array}{l}\text { Relacionamento e } \\
\text { corresponsabilidade }\end{array}$ & $\begin{array}{l}\text { - Relacionamento e colaboração } \\
\text { - Corresponsabilidade }\end{array}$ \\
\hline Solução e criatividade & $\begin{array}{l}\text { - Visão crítica } \\
\text { • Foco em solução } \\
\text { - Criatividade }\end{array}$ \\
\hline Difusão e multiplicação & $\begin{array}{c}\text { - Registro de boas práticas } \\
\text { • Difusão } \\
\text { • Multiplicação }\end{array}$ \\
\hline
\end{tabular}

Fonte: SEESP, Tutorial de Recursos Humanos. Programa de Ensino Integral, SEESP, 2014.

Concordante com o abandono de uma avaliação unilateral, na avaliação $360^{\circ}$, como mencionado, docentes e diretores escolares (gestores) serão, nessa etapa, examinados - com base nas competências apresentadas no Quadro 2 - por: estudantes, supervisor de ensino, dirigente de ensino e professor coordenador da Oficina Pedagógica da Diretoria de Ensino.

Destaque-se que, para cada competência, há a indicação de: macroindicadores, acerca das expectativas profissionais para cada segmento profissional; e, microindicadores que detalham as respectivas expectativas comportamentais.

De acordo com a SEESP,2014:

Esse modelo de competências permite o alinhamento das diversas frentes da gestão 
de desempenho dos profissionais no Programa, desde a avaliação de candidatos do processo de credenciamento à avaliação dos profissionais que já atuam em Regime de Dedicação Plena e Integral, bem como o desenvolvimento de plano de formação e de reconhecimento de profissionais. Para cada competência, foram desenvolvidos macroindicadores que definem o comportamento esperado no âmbito da competência e, em seguida, os microindicadores que detalham esse comportamento para cada função do modelo. (SÃO PAULO, Tutorial de Recursos Humanos, 2014, p.17).

O processo ocorre por meio do preenchimento de um questionário eletrônico disponibilizado no Sistema de Avaliação das Equipes Escolares do Programa Ensino Integral, no âmbito da Secretaria Escolar Digital (SED), e cada avaliador deve assinalar, para cada competência, a frequência com que o profissional em julgamento apresentou determinado comportamento no desenvolvimento do seu trabalho, ao longo de cada semestre.

A mensuração obedece uma escala que contempla, ao menos, dois equívocos metodológicos, quais sejam: a) apresenta quatro variações, e não cinco ou mais. Isso significa dizer, com base em Selltiz et al (1987), que as opiniões serão concentradas fundamentalmente nos aspectos positivos ou negativos, sem possibilidades de posições intermediárias. São elas: sempre (4), quase sempre (3), às vezes (2), raramente ou nunca (1); b) desconsidera o caráter subjetivo presente em cada resposta da escala, pois a compreensão individual a respeito da escala é variável e já confere, por si só, indicativos relativos e dúbios sobre os comportamentos.

Dessa forma, todos os participantes do processo contam com atribuições, conforme sua posição na hierarquia da SEESP, conforme indica o Quadro 3:

\section{Quadro 3 - Participantes e suas atribuições na avaliação $360^{\circ}$}

\begin{tabular}{|c|c|}
\hline Professores e Gestores & Realizam a Autoavaliação \\
\hline Professores & Avaliam seus pares e equipe gestora \\
\hline Equipe gestora & $\begin{array}{c}\text { Avalia os professores e cada profissional da gestão escolar Diretor, Vice Diretor, } \\
\text { PCG e PCA*, porém, o PCA não avalia o Diretor e Vice Diretor, assim como o Vice } \\
\text { Diretor não avalia o PCA }\end{array}$ \\
\hline Alunos & Avaliam professores e equipe gestora, exceto PCA \\
\hline Supervisor de Ensino & Avalia a equipe gestora, exceto o PCA \\
\hline Dirigente & Avalia o Diretor da Escola \\
\hline PCNP* $^{*}$ & Avalia o Professos Coordenado Geral - PCG e o Vice Diretor \\
\hline
\end{tabular}

Professor Coordenador do Núcleo Pedagógico - PCOP. * Professor Coordenador por Area PCA. * Professor Coordenador Geral - PCG

Fonte: SEESP, Tutorial de Recursos Humanos. Programa de Ensino Integral, 2014 Elaboração própria 
Além dessa avaliação eletrônica há outra que abarca o comprometimento junto ao PEI de cada profissional e é realizada pela equipe gestora, PCNP e supervisor de ensino. Observa-se que a análise da assiduidade registra as ausências independente do motivo, à exceção das licenças gestante e paternidade e finda por se configurar como mais uma forma de controle dos profissionais, a exemplo do que ocorre com os critérios para a realização da Prova do Mérito ${ }^{10}$, na qual é preciso abdicar de direitos conquistados para ter direito a concorrer ao aumento salarial. ${ }^{11}$

Logo, a avaliação $360^{\circ}$ é composta pela união de resultados dos questionários mencionados, os quais são gerados automaticamente pela plataforma do PEI e pela avaliação do comprometimento.

Decorrente desse preenchimento são realizadas reuniões individuais entre os profissionais e a equipe gestora para a apresentação dos resultados da avaliação. Esses momentos objetivam efetivar uma nova etapa do processo de avaliação denominada pela SEESP, 2014 'calibragem'”, que consiste na verificação das evidências do comportamento esperado por cada profissional no cotidiano do seu trabalho, resultando em aumento ou diminuição de um ponto na média final em cada competência apreciada.

A pontuação final da avaliação das competências e dos resultados de cada profissional é inserida em um quadrante composto por nove faixas, cuja pontuação total das competências é apontada verticalmente e a avaliação dos resultados horizontalmente.

É importante lembrar que, de acordo com a Resolução ${ }^{12}$ que normatiza a avaliação de desempenho, o docente que não lograr uma apreciação positiva será desligado do Programa.

Ressalte-se que, para a participação, os profissionais devem dedicar-se exclusivamente ao programa, não sendo permitidos outros contratos de emprego, e recebem bonificação equivalente a $75 \%$ do salário base, mediante Regime de Dedicação Plena e Integral, ou seja, desempenho da função docente em jornada de trabalho semanal de 40 horas $^{13}$.

Procede-se, para tanto, a um cruzamento para definição do quadrante final de cada profissional.

10 Lei Complementar n. 1097 de 27 de outubro de 2009

11 Sobre isso ver: Gonçalves, E, Venco, S. Prova do mérito: progressão na carreira mediante violação de direitos. Disponível em < Prova do mérito: progressão na carreira mediante violação de direitos $>$ Acesso em 30.maio.2019

12 Resolução SE-68, de 17-12-2014

13 Lei Complementar no 1.164, de 4/01/2012. Institui o Regime de Dedicação Plena e Integral - RDPI e a Gratificação de Dedicação Plena e Integral 


\section{Quadro 4 - Quadrantes da Avaliação dos Resultados}

\begin{tabular}{|c|c|c|c|c|}
\hline \multirow{7}{*}{$\begin{array}{l}\text { Avaliação de } \\
\text { Competências }\end{array}$} & \multirow[b]{2}{*}{1 a 4} & 03 & 06 & 09 \\
\hline & & Observação & $\begin{array}{l}\text { Alto desempenho } \\
\text { por competência }\end{array}$ & $\begin{array}{l}\text { Potencial além da } \\
\text { função }\end{array}$ \\
\hline & \multirow[b]{2}{*}{2,1 a 3} & 02 & 05 & 08 \\
\hline & & $\begin{array}{l}\text { Melhoria em } \\
\text { resultado }\end{array}$ & $\begin{array}{l}\text { Transforma } \\
\text { potencial em } \\
\text { desempenho }\end{array}$ & $\begin{array}{l}\text { Alto desempenho } \\
\text { por resultado }\end{array}$ \\
\hline & \multirow[b]{2}{*}{1 a 2} & 01 & 04 & 07 \\
\hline & & $\begin{array}{c}\text { Riscos na } \\
\text { manutenção do } \\
\text { profissional }\end{array}$ & $\begin{array}{c}\text { Melhoria em } \\
\text { comportamentos }\end{array}$ & Requer análise \\
\hline & & 1 a 2 & 2,1 a 3 & 3,1 a 4 \\
\hline & \multicolumn{4}{|c|}{ Avaliação de Resultados } \\
\hline
\end{tabular}

Fonte: SEESP. Modelo de Desempenho da Equipes escolares, 2014

Dessa forma, apreende-se que há padrões definidos de comportamentos e, subentendido um tipo de prescrição a ser cumprido pelos profissionais. A partir do resultado da avaliação, a reunião de "calibragem" irá estabelecer readequações aos envolvidos, conforme indicado no Quadro 4 transcritas ipsis litteris do documento SEESP, 2014, a fim de ampliar a compreensão sobre as diretrizes estabelecidas:

\section{Quadro 4 - Ações do gestor, conforme resultado da avaliação}

\begin{tabular}{|c|l|}
\hline Quadrante & \multicolumn{1}{c|}{ Descrição } \\
\hline Q1 & $\begin{array}{l}\text { É necessário que o gestor acompanhe de forma próxima e invista na formação do profissional, } \\
\text { observando se há sinais de evolução. Caso essa evolução não aconteça, este 'deverá ser } \\
\text { cessado do Programa'. Avaliar se o profissional está na função errada e se há possibilidade } \\
\text { de ser recolocado. }\end{array}$ \\
\hline Q2 & $\begin{array}{l}\text { É necessário entender o que o impede de entregar melhores resultados. O que o está } \\
\text { atrapalhando? Do que ele precisa para melhorar os resultados? O profissional apresenta } \\
\text { as competências necessárias (ainda que parcialmente), mas pode estar desmotivado a } \\
\text { executar suas ações do Programa. Desenvolver formas de aumentar seu empenho em } \\
\text { melhorar a entrega. Investir em formação pode ser uma opção. }\end{array}$ \\
\hline Q3 & $\begin{array}{l}\text { É um profissional que tem potencial para entregar resultados, mas não está conseguindo } \\
\text { colocar em prática suas capacidades. Pode ser alguém novo para a função ou que está tendo } \\
\text { dificuldades de se adaptar ao Programa Ensino Integral. Entender o que o está impedindo de } \\
\text { executar suas ações no Programa e desenhar com ele um plano para que possa progredir. }\end{array}$ \\
\hline Q4 & $\begin{array}{l}\text { É um profissional que conhece seu trabalho (pode ser um especialista), sendo capaz de } \\
\text { apresentar resultados do Programa de Ação, ainda que parciais. No entanto, não é percebido } \\
\text { como alguém com o perfil comportamental esperado para a função no Programa Ensino } \\
\text { Integral. É necessário implementar ações para desenvolver as competências esperadas. }\end{array}$ \\
\hline
\end{tabular}




\section{Quadro 4-Ações do gestor, conforme resultado da avaliação}

\begin{tabular}{|c|l|}
\hline Quadrante & \multicolumn{1}{c|}{ Descrição } \\
\hline Q5 & $\begin{array}{l}\text { Entrega as ações previstas em seu Programa de Ação e é percebido como alguém que } \\
\text { apresenta as competências esperadas para a função no Programa Ensino Integral (ainda } \\
\text { que ambos de forma parcial). É onde se espera que a maior parte dos profissionais estejam } \\
\text { posicionados. É necessário considerar suas lacunas de resultados e desenvolvimento } \\
\text { das competências e desenhar ações para que ele possa transformar seu potencial em } \\
\text { desempenho. }\end{array}$ \\
\hline Q6 & $\begin{array}{l}\text { É o profissional visto como aquele que apresenta as competências necessárias para a função } \\
\text { no Programa Ensino Integral. Pode ser considerado um modelo de referência em algumas } \\
\text { competências para outros profissionais. Além disso, apresenta resultados do seu Programa } \\
\text { de Ação (ainda que parciais). Considerar colocá-lo em projetos desafiadores ou com papel de } \\
\text { liderança para estimular suas entregas e potencializar o uso de suas competências. }\end{array}$ \\
\hline Q7 & $\begin{array}{l}\text { É um ótimo profissional em termos de execução do seu Programa de Ação, mas precisa } \\
\text { desenvolver suas competências. Pode ser alguém que conhece bem sua função, mas que } \\
\text { não está se adaptando ao Programa de Ensino Integral. É necessário elaborar um plano de } \\
\text { desenvolvimento que o estimule a se desenvolver nas competências esperadas, de modo } \\
\text { que possa desempenhar os comportamentos necessários. }\end{array}$ \\
\hline Q8 & $\begin{array}{l}\text { É alguém que apresenta as competências necessárias para a função (ainda que parcialmente) } \\
\text { e entrega resultados do seu Programa de Ação de maneira excepcional. É necessário } \\
\text { considerar colocá-lo em projetos desafiadores, que demandem resultados, de modo que } \\
\text { se aproveite seu potencial e suas competências comportamentais sejam potencializadas. }\end{array}$ \\
\hline Q9 & $\begin{array}{l}\text { É um profissional excepcional em termos de competências e resultados. É conhecido como } \\
\text { o grande talento da instituição. É uma pessoa que ajuda a escola a evoluir e atingir melhores } \\
\text { resultados. Avaliar se poderia assumir uma função de maior complexidade (um professor } \\
\text { poderia assumir a função de um PCA, por exemplo). Oferecer oportunidades de potencializar } \\
\text { seu desenvolvimento (cursos, projetos etc.) e papéis que Ihe permitam desenvolver o } \\
\text { potencial de outros profissionais. }\end{array}$ \\
\hline
\end{tabular}

Fonte: SEESP. Modelo de Desempenho da Equipes escolares, 2014, pp. 27,28. Grifos nossos

A devolutiva da avaliação de cada profissional é realizada pela Equipe Gestora, PCNP e Supervisor de Ensino. É um momento em que professores e gestores, de forma individual, tomam conhecimento do resultado da avaliação $360^{\circ}$ e elaboram seu Plano Individual de Aprimoramento e Formação (PIAF), o qual está prescrito no Cardápio I - Ações formativas autônomas, de acordo com o resultado da avaliação $360^{\circ}$.

Observa-se que nesse processo o gestor da escola exerce um papel fundamental, na medida em que fica sob sua responsabilidade o acompanhamento da formação dos profissionais, conforme os direcionamentos contidos no 'Cardápio de Ações Formativas'.

Assim, a análise dos documentos referentes à avaliação $360^{\circ}$ indica a centralidade que a ferramenta assume na consolidação de "perfis desejados" no Programa. As orientações de caráter objetivo desconsideram, portanto, a subjetividade dos profissionais da escola, suas circunstâncias momentâneas ou permanentes de vida, as quais podem vir a interferir no campo profissional.

A avaliação $360^{\circ}$ conta, portanto, com seis etapas organizadas e os respectivos atores em cada uma delas, conforme indicado no Quadro 5. 


\section{Quadro 5 - Síntese da avaliação $360^{\circ}$}

\begin{tabular}{|c|c|}
\hline Ação & Quem avalia? \\
\hline $\begin{array}{c}\text { Avaliação eletrônica- } \\
\text { Questionário }\end{array}$ & Alunos, professores, equipe gestora, supervisor e \\
PCNP
\end{tabular}

Fonte: SEESP, Modelo de Desempenho da Equipes escolares, 2014

Elaboração própria

As entrevistas realizadas junto aos gestores permitem afirmar que a aplicação da avaliação 360 graus consome tempo expressivo para seu desenvolvimento, um tempo caro frente a um conjunto de demandas e exigências para a consolidação do PEI. E afirmam, diferentemente dos autores favoráveis

Além disso, afirmam que com a adoção desse tipo de avaliação e diferente da constatação dos autores favoráveis a tal prática, o julgamento feito entre os pares cria um clima organizacional nefasto no interior das escolas.

As ponderações recaem para o abandono crescente, por parte dos docentes, ao Programa. Para os entrevistados, a bonificação de $75 \%$ deixa de ser atrativa aos profissionais à medida em que se veem submetidos a um forte controle sobre suas atividades profissionais, tangenciando a tentativa de prescrever o trabalho intelectual e indo de encontro às perspectivas de exercício da docência almejadas. Nesse sentido, os diretores de escola apontam para dificuldades na obtenção e permanência de professores nas escolas PEI, sendo necessário, inclusive, fazer uso de contratos temporários para suprir a ausência de pessoal.

\section{CONSIDERAÇÕES FINAIS}

O artigo buscou problematizar a adoção de um tipo de avaliação de desempenho que reforça, mais uma vez, o caráter gerencialista da política educacional paulista: a avaliação 360 graus.

Essa feita pelos pares, por meio de questionários eletrônicos e voltadas estritamente à análise comportamental e à identificação de lideranças, remete à conclusão de que as formas de avaliação aplicadas no estado de São Paulo afastam- 
se de perspectivas que resultem efetivamente em saldos qualitativos à educação e aos profissionais nela envolvidos.

A SEESP permanece coerente em sua concepção de educação calcada no pragmatismo empresarial e toma como interlocutores privilegiados as empresas e as consultorias tradicionalmente voltadas para estudos setoriais com visões marcadamente unilaterais.

Por outro lado, os profissionais da educação permanecem silenciados na construção das políticas e, nos parece, envolvidos em um tipo de avaliação que subtrai o diálogo e despreza o trabalho coletivo.

Um estudo sobre os efeitos psicológicos sobre o uso de tais práticas junto aos diretores e professores deveria ser feita, cujos resultados, possivelmente, serão desastrosos do ponto de vista humano.

\section{REFERENNCIAS}

BACON, K. Além da capacitação: desenvolvimento de líderes para o setor público. Revista do Serviço Público, ano 50 Número 4, Out-Dez 1999.

BAKUNIN, M.. La instrucción integral. Barcelona: José Olañeta Editor, 1979

BRACKEN, David W., Carol W. TIMMRECK, John W. FLEENOR, and Lynn SUMMERS. 360 feedback from another angle. Human Resource Management, Spring 2001, Vol. 40, No. 1, Pp. 3-20

BRANDÃO, Hugo Pena , GUIMARÃES, Thomas de Aquino. GESTÃO DE COMPETÊNCIAS E GESTÃO DE DESEMPENHO: tecnologias distintas ou instrumentos de um mesmo construto? RAE - Revista de Administração de Empresas. SP, vol. 41, n.1. Jan./Mar. 2001. Disponível em < http://www.scielo. br/pdf/rae/v41n1/v41n1a02.pdf $>$ Acesso em 14.fev.2018

BRASIL, Ministério de Educação e Cultura. LDB - Lei no 9394/96, de 20 de dezembro de 1996. Estabelece as diretrizes e bases da Educação Nacional. Brasília: MEC, 1996

CORBIN, Alice Katherine. 360-Degree Feedback. SSRN Electronic Journal, January 2012. Disponível em https:/ / papers.ssrn.com/sol3/ papers.cfm?abstract_ id=2288194 Acesso em 15.fev.2018 
DURAND, Thomas. L'alchimie de la compétence. Revue française de gestion $-\mathrm{N}^{\circ} 160 / 2006$.

HALVERSON, Stefanie K., TONIDANDEL, Scott, BARLOW, Cassie, Robert L. DIPBOYE. Self-Other Agreement on a 360-Degree Leadership Evaluation. Comunicação apresentada no XVII Annual Conference of the Society for Industrial and Organizational Psychology, Toronto, Canadá, 2002. Disponível em< https://www.academia.edu/24629271/Self-other_agreement_ on_a_360-degree_leadership_evaluation> Acesso em 14.fev.2018

NEESHU. M. 360 Degrees Performance Appraisal. IRACST- International Journal of Research in Management \& Technology. Vol.6, No.1, Jan-Feb 2016

OCDE. Education at a glance. Disponível em <https://read.oecd-ilibrary. org/education/education-at-a-glance-2018_eag-2018-en\#page1>. Acesso em 27.maio.2019

BERTAGNA, R. et al. As avaliações em larga escala e o currículo no estado de São Paulo: a realidade escolar desvelando as lógicas subjacentes. Currículo sem Fronteiras. Disponível em < http://www.curriculosemfronteiras.org/ vol18iss1articles/bertagna-polato-mello.pdf $>$ Acesso em 18.set.2018

FONSECA, M. Políticas públicas para a qualidade da educação brasileira: entre o utilitarismo econômico e a responsabilidade social. Cad. CEDES, Campinas, v. 29, n. 78, p. 153-177, 2009 .

JAEGER, Werner. A formação do homem grego. São Paulo: Martins Fontes, 1995.

PARO, V. H. et al. Escola de tempo integral: desafio para o ensino público. 1. ed. São Paulo: Cortez; São Paulo: Autores Associados, 1988. 232 p.

ROPÉ, Françoise; TANGUY, Lucie (org). Saberes e competências: o uso de tais noções na escola e na empresa. Campinas: Papirus, 1997 
SÃO PAULO (Estado). Lei Complementar $n^{\circ} 1.164$ de 4 de janeiro de 2012. Disponível em https://www.al.sp.gov.br/repositorio/legislacao/lei. complementar/2012/lei.complementar-1164-04.01.2012.html acesso em $01 / 10 / 2017$.

(Estado). Secretaria de Educação. Diretrizes do Programa Ensino Integral, Caderno do Gestor. $1^{a}$ edição. São Paulo, São Paulo: SEE 2014. Disponível em http://www.educacao.sp.gov.br/a2sitebox/arquivos/documentos/342.pdf acesso em 01/02/2017.

(Estado). Secretaria da Educação. Educação. A Nova Estrutura Administrativa da Secretaria da Educação do Estado de São Paulo: Por uma Gestão de Resultado com Foco no Desempenho do Aluno, São Paulo: SEE 2013. Disponível em http://www.educacao.sp.gov.br/a2sitebox/arquivos/ documentos/572.pdf acesso em 23/08/2017.

(Estado). Secretaria da Educação. Modelo de Gestão de Desempenho das Equipes Escolares - Caderno do Gestor. $1^{a}$ edição. São Paulo, São Paulo: SEE 2014.

. (Estado). Secretaria da Educação. Diretrizes do Programa de Ensino Integral. São Paulo: SEE, 2012. Disponível em: <http://www.educacao.sp.gov. $\mathrm{br} / \mathrm{a} 2$ sitebox/arquivos/documentos/726.pdf>. Acesso em 08/12/2017.

- (Estado). Secretaria da Educação. Manual de gestão das Escolas Estaduais de Ensino Médio de Período Integral. Modelo de gestão educacional de São Paulo. São Paulo: SEE, 2012.

(Estado) Secretaria da Educação. Informações Básicas do Programa de Ensino Integral. São Paulo: SEE, 2012. Disponível em: <http://www. educacao.sp.gov.br/a2sitebox/arquivos/documentos/727.pdf>. Acesso em: $<04 / 12 / 2017>$

. (Estado). Secretaria da Educação. Tutorial de Recursos Humanos. Programa de Ensino Integral. São Paulo: SEE, 2014. Disponível em: http:// www.educacao.sp.gov.br/a2sitebox/arquivos/documentos/734.pdf acesso em $12 / 12 / 2017$. 
.(Estado). Secretaria da Educação. Formação das Equipes do Programa de Ensino Integral, Vol. I, São Paulo: SEE,2014.

.(Estado). Secretaria da Educação. Cardápio I - Ações formativas autônomas. Plano Individual de Aperfeiçoamento e Formação, São Paulo: SEE,2015.

.(Estado). Secretaria da Educação. Currículo do Estado de São Paulo, São Paulo: SEE,2008

Secretaria da Educação. Tutorial Gestão de desempenho/Avaliação de desempenho, São Paulo: SEE, 2018.

SELLTIZ, C. et al. Métodos de pesquisa nas relações sociais. São Paulo: EPU, 1987.

VENCO, Selma. Tempo eeducação: reflexões sobreFrançae Alemanha.Educação: Teoria e Prática, vol27.n56, 2017. Disponível em < http://www.periodicos. rc.biblioteca.unesp.br/index.php/educacao/article/view/11958/8347> Acesso em 30.maio.2019

TAYLOR, F. Princípios de Administração Científica. São Paulo: Atlas, 1990.

WALDMAN, D., ATWATER, L. E., ANTONIONI, D. Has 360 Degree Feedback Gone Amok? The Academy of Management Executive (1993-2005). Vol. 12, No. 2 (May, 1998), pp. 86-94

SELMA BORGHI VENCO é Socióloga, mestre e doutora em educação pela Universidade Estadual de Campinas, com doutorado-sanduíche na Université Paris $\mathrm{X}$, Nanterre. Foram realizados dois pós-doutoramentos: IFCH, departamento de sociologia; e Laboratoire Genre, Travail et Mobilités, Univeristé Paris X. Docente na Faculdade de Educação da Universidade Estadual de Campinas (UNICAMP), Departamento de Políticas, Administração e Sistemas Educacionais (DEPASE); Pesquisadora associada do Centre de Recherches Sociologiques et Politiques de Paris (CRESPPA) e Vice-líder do Grupo de Estudos e Pesquisas em Política 
Educacional (GREPPE). A Nova Gestão Pública e as relações de trabalho praticadas no setor público educacional têm sido focos privilegiados de estudos e pesquisas desde 2010. Atualmente desenvolve estudo comparativo FrançaBrasil sobre o mesmo tema. Foi vice-presidente do Centro de Estudos Educação e Sociedade - CEDES (2014-2018) e atual membro permanente do Conselho Científico do Núcleo de Estudos de Gênero PAGU. E-mail: selma.venco@ gmail.com

ORCID: https://orcid.org/0000-0002-2637-3687

ROSEMARY MATTOS é Pedagoga (PUCC), mestre em educação (Unimep, 2012), doutoranda do Programa de Pós-graduação em Educação (Unicamp). Supervisora de ensino na Secretaria de Estado da Educação de São Paulo. Membro do Conselho Municipal de Educação do município de Estiva Gerbi/SP. A gestão educacional e o trabalho dos diretores de escola no estado de São Paulo são temas da pesquisa em desenvolvimento.E-mail: rosemattos09@hotmail.com

Recebido em junho de 2019

Aprovado em julho de 2019 